\title{
LFS Single Month Analysis (Not designated as National Statistics)
}

\author{
Author Name(s): Chris Phillips, Office for National Statistics
}

\begin{abstract}
Movements in the LFS data series at the end of 2003 prompted ONS to conduct detailed analysis of the LFS data to determine the reasons behind these movements. Experimental analysis of the data, at the highest aggregate level, was carried out to break the LFS data down into single month periods. This analysis proved useful so has since been produced every month.
\end{abstract}

\section{Single Month LFS Analysis}

\section{Background}

Movements in the LFS data series at the end of 2003 prompted ONS to conduct detailed analysis of the LFS data to determine the reasons behind these movements. Experimental analysis of the data, at the highest aggregate level, was carried out to break the LFS data down into single month periods. This analysis proved useful so has since been produced every month.

As the 3-month average of the single month series tracks the changes seen in the published LFS, it is possible to consider changes in the published LFS in terms of movements in the experimental single month series. This in turn makes it easier to determine whether the movements in the published LFS series are true reflections of changes in the wider economy, or whether they are movements that reflect the survey nature of the LFS and its sensitivity to factors such as sampling error.

\section{Method}

Briefly, single month LFS estimates were produced by taking the raw, or unweighted, LFS survey responses for each month and weighting them up to single month population estimates, using a simplified weighting method (broad age band and sex). These single month estimates were then seasonally adjusted. By constructing a 3-month average of the seasonally adjusted single month series and comparing this with the published LFS (itself a 3-month average), it was possible to show that the average of the experimental single month series tracked the changes in the published series. The two series were not identical, however, due to the relative crudity of the weighting method used to produce the single month estimates. This tended to slightly overemphasise the weighting of those with higher employment rates. To remove the differences between the single 
month and published LFS, the single month series was benchmarked to the published LFS series, using a set of iterative equations. Further details of the method are included in the technical note at the end of this paper.

\section{Charts}

The charts in this briefing show the published and single month estimates for employment, unemployment and inactivity (seasonally adjusted). For the published series, the dates shown relate to the last month of the three (e.g. January - March is shown as March).

\section{UK Employment Rates (16-64) Seasonally Adjusted}

The figure for August 2011 shows an increase of 0.2 percentage points on the previous month.

\section{UK 16-64 Employment Rates (Seasonally Adjusted)}

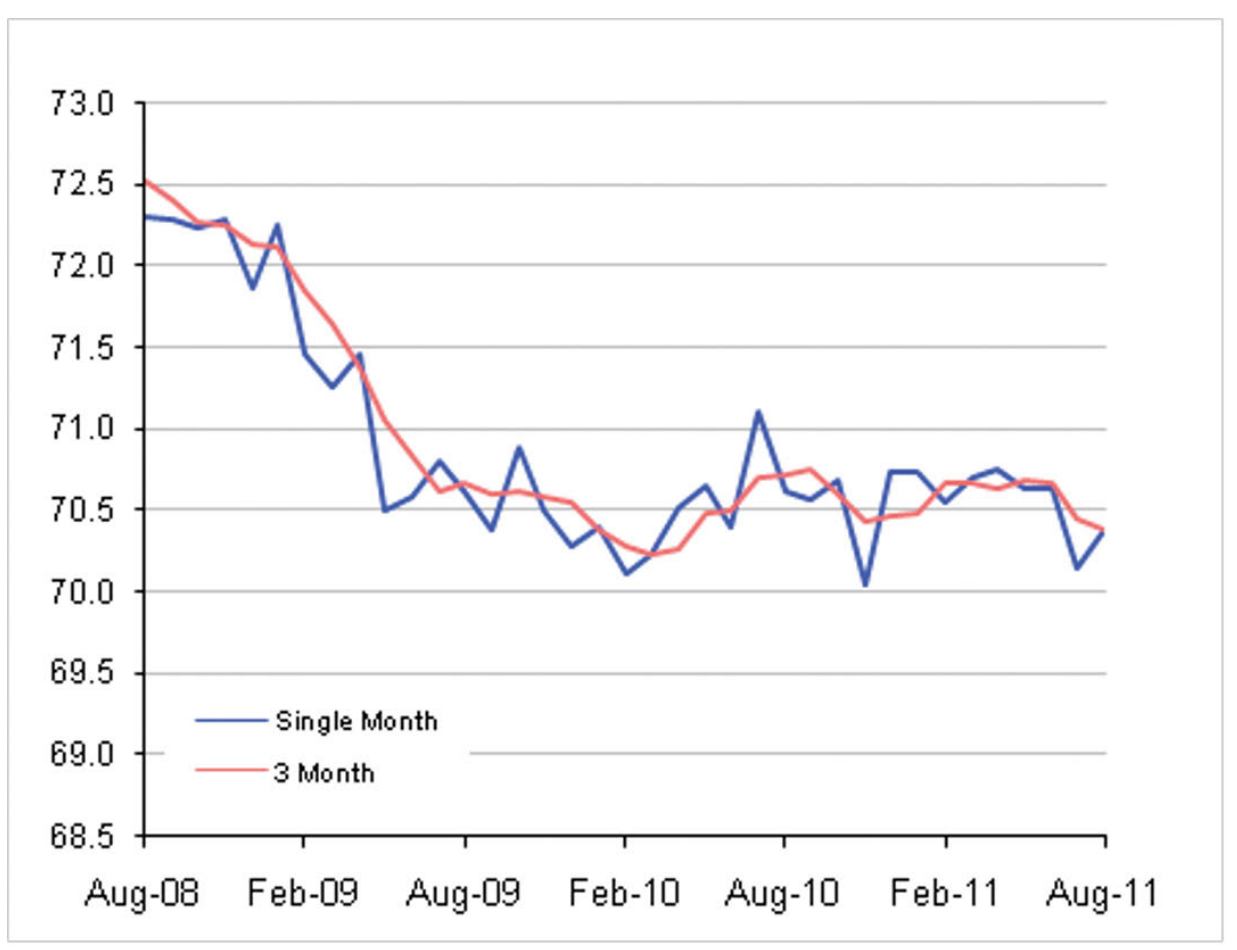

Source: Labour Force Survey - Office for National Statistics

\section{Download chart}

XLS XLS format

$(128 \mathrm{~Kb})$

\section{UK 16+ Unemployment Rates (Seasonally Adjusted)}

The figure for August 2011 shows an increase of 0.2 percentage points on the previous month. 


\section{UK 16+ Unemployment Rates (Seasonally Adjusted)}

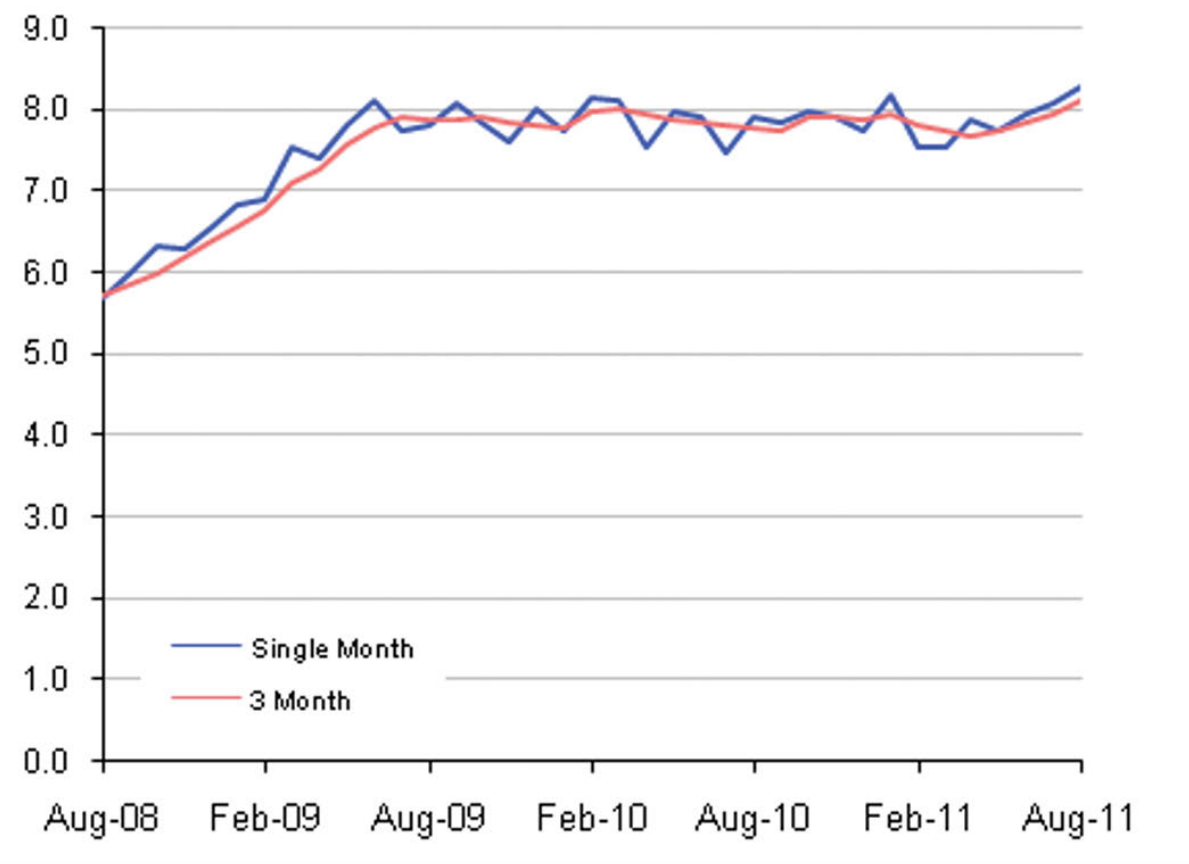

Source: Labour Force Survey - Office for National Statistics

\section{Download chart}

XLS XLS format

$(128 \mathrm{~Kb})$ 


\section{UK 16-64 Inactivity Rates (Seasonally Adjusted)}

UK 16-64 Inactivity Rates (Seasonally Adjusted

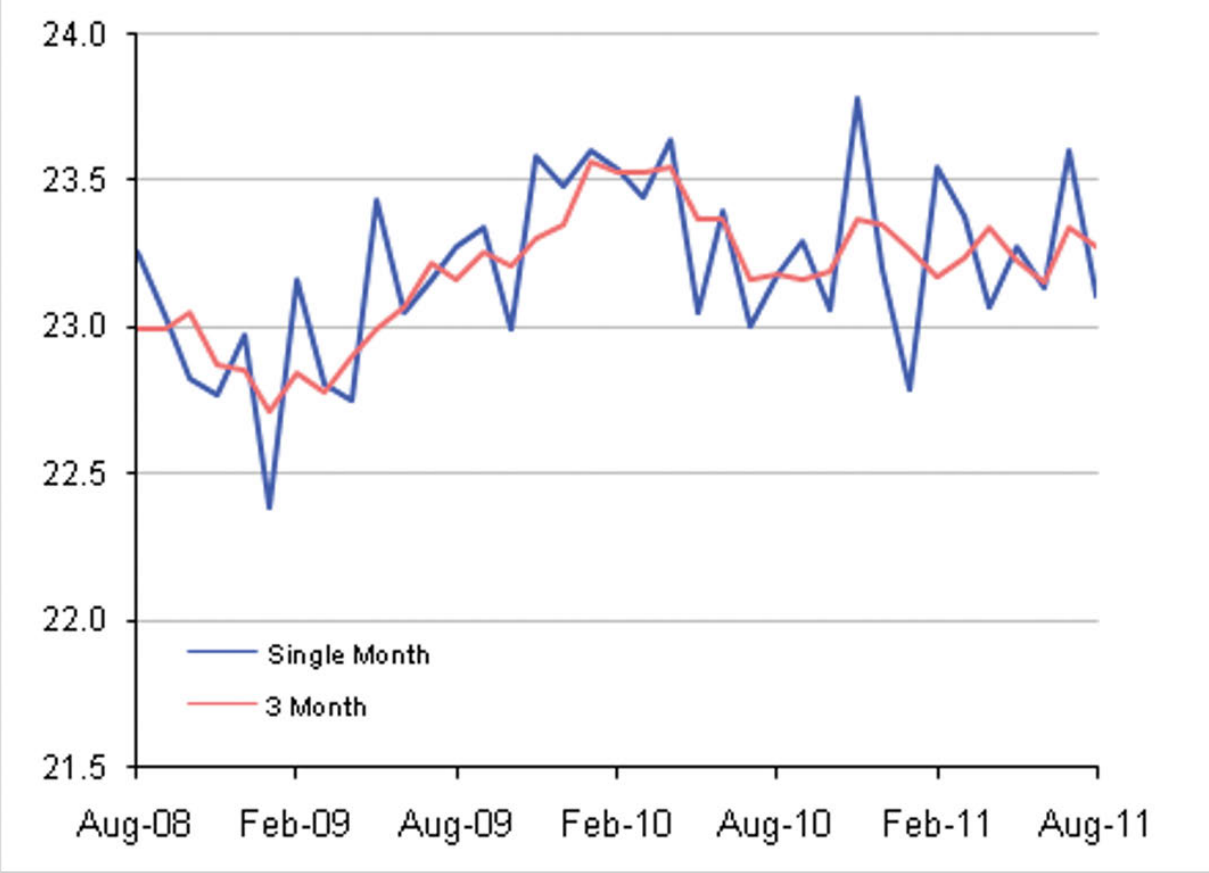

Source: Labour Force Survey - Office for National Statistics

Download chart

XLS XLS format

$(128 \mathrm{~Kb})$

\section{Methodological article}

A methodological article about these estimates is available on the website. 